\title{
The strengths and weaknesses of written English of black high school pupils
}

Erna Alant

\begin{abstract}
This study attempts to identify some of the strengths and weaknesses of the English of black high school pupils. A random sample of pupils from three classes in each of two schools was selected and given a battery of tests consisting of essay writing, spelling, word usage and punctuation. The method of evaluation of the test battery is described. The results of the tests are outlined and suggestions for the development of an intervention programme are given.
\end{abstract}

Hierdie artikel poog om sommige van die swakhede sowel as die sterk punte van die Engels van swart hoërskoolleerlinge te identifiseer. 'n Ewekansige steekproef van leerlinge van drie klasse in twee afsonderlike skole is gekies en 'n reeks toetse bestaande uit opstel skryf, spel, woordgebruik en punktuasie is gegee. Die skryfster beskryf die metode van evaluasie van die toetsreeks, skets die uitslae van die toets en gee voorstelle vir die ontwikkeling van 'n intervensie-program.

\section{Background}

The importance of second language teaching has received much attention among educationists and linguists for several decades. One of the reasons for this is the realization that language facilitates cross-cultural contacts. As South Africa is characterized by many different cultural and language groups, the necessity for bilingualism is obvious.

For black South Africans, the acquisition of a second language, particularly English, not only provides a basis for cross-cultural contacts within a culturally plural society, but is also the major means of access to the education system, the job market and the urban-industrial complex in general. For example, the mastery of English will to a large extent determine a student's performance in secondary and tertiary education, as English is the medium of instruction at these levels. The degree of fluency in English will therefore also influence the quality of life of the student.

In spite of the many reasons for being fluent in English, the average proficiency of black students in English has caused great concern over the last decade. Researchers (Odendaal 1986, Malefo 1986, Mawasha 1986) have commented on the English language problems of students as well as teachers in the schools. They point out that apart from the language problems which the children experience, teachers also have difficulty in expressing themselves through the medium of English. Odendaal (1986) describes some of the problems she identified in KwaZulu primary schools as: incorrect use of conjunctions and relative pronouns, wrong choice of words and illogical sequencing of thoughts.

Educationists at primary, secondary and tertiary level have expressed the need for greater language proficiency of students, as is shown by the following statement: 
"Sadly, I have come to the conclusion that Unitra (University of the Transkei) students do not speak or write English as a medium of instruction, let alone comprehend it. What they produce is an extraordinary compound, the substructure of which is Nguni syntax with a superficial overlay of English words" (Gardner 1986:185).

Furthermore, Gardner (1986) mentions the influence of structural aspects of the mother tongue on the second language. This is a frequently acknowledged phenomenon in the learning of a second language (Burt, Dulay and Finocchiaro 1977, Dulay, Burt and Krashen 1982, Ovando and Collier 1985). Ovando and Collier (1985:65) emphasize that this influence is not necessarily negative and that "Studies over the last decade and a half have increasingly shown that L1 has a predominantly positive influence on L2, rather than the negative impact implied by the term 'interference'." Krashen and Terrell (1983) agree with this approach and point out that errors which show the influence of the first language are the result of 'falling back' on the first language when the student lacks a rule in the second language. They suggest that the cure for interference does not lie in "fighting off" the influence of the first language, but merely by helping the student acquire the target language.

There are certain contexts in which the influence of the first language becomes more evident. Some of these have been identified as pronunciation, particularly with adult learners, when the students are expected to produce the second language before having had enough exposure to the new language, and the natural linguistic borrowing and code-switching that occur in any situation where two languages come in contact (Ovando and Collier 1985:64).

The complexity of learning a second language and the demands made in terms of a different perspective on reality are emphasized by Malefo (1986:3) when he states that "Language is also the most important manifestation of a culture". He goes on to describe the dilemma for the black child who "lives in a world that is a combination of two or three or even more cultures". Apart from the child's mother-tongue, the child has to learn English and Afrikaans in order to function in the broader community even though the child gets limited opportunities to interact with mother-tongue speakers of those two languages. This aspect is also complicated by the fact that English at school is not taught by mother-tongue speakers; this would be impracticable, as Mawasha (1986:9) explains:

"The mistaken notion that teachers who teach English or use it as medium should be mothertongue speakers of English needs to be buried once and for all. It is logistically impracticable to man all black schools with English first language speakers; it is mischievous to say that black people are inherently incapable of learning and mastering English. Black teachers can and must be trained to use English effectively as a medium of communication and to use it to advantage as a medium of teaching and learning."

It is against this background that more research into the kinds of difficulties experienced by teachers and students becomes crucial. The better the understanding of the language problems experienced by the students, the more effective intervention strategies will be.

\section{Aim of the study}

The aim of this study is to identify the language strengths and weaknesses of black high school pupils in order to provide a basis for the development of intervention programmes for the acquisition of skills in English.

Although a relatively small sample of subjects was used, it provides a sufficient basis for the development of an initial programme which may then be refined to cater for a greater diversity of needs and age-groups.

\section{METHODOLOGY}

\section{SUBJECTS}

Two schools were selected for inclusion in the main study. These were both community schools and 
included one school with an established academic record and another relatively new school with a less established academic record. These observations are based on the perceptions of community leaders and inspectors of the Department of Education and Training. It was also felt that the inclusion of both these schools would give an adequate reflection of the average language ability of high school pupils in the area.

Sample: Three classes (Standards six, eight and ten) were selected from each school. After discussions with the school principals, the random selection of pupils for inclusion in the study was conducted as follows:

(i) Where classes were grouped according to subject choice, one class was randomly selected by the researcher.

(ii) Where classes were grouped according to academic achievement, the sample was selected by drawing equal numbers of children from the different classes to ensure a representative sample.

Altogether 255 children were included in the main study, of which 215 answer sheets were analysed.

TABLE 1 Description of students

\begin{tabular}{ccc}
\hline Standard & Number & Average age \\
\hline 6 & 87 & 14,17 (SD 1,37) \\
8 & 66 & 15,71 (SD 4,24) \\
10 & 67 & 19,70 (SD 1,31) \\
\hline
\end{tabular}

\section{TESTING PROCEDURE:}

The following procedure was used based on the findings of the pilot study (Alant 1987):

1 Each class was given a test lasting 60 minutes.

2 The researchers were introduced to the pupils, who were then supplied with pens.

3 It was stressed that this was not a test that could be failed, but that its purpose was to help the researchers identify the areas of strength and difficulties in the pupils' written English.

4 The following times were allocated for each subtest:

Essay: 20 minutes

Spelling: 10 minutes

Word Usage: 10 minutes

Punctuation: 10 minutes

\section{TEST MATERIAL}

The Test of Written Language (Hammill and Larsen 1978) was used and modified for inclusion in this research (Alant 1987). This specific test was chosen as it is one of the most recent and widely used measures of written language although it has not yet been applied to Black pupils in South Africa.

The main modification made based on the findings in the pilot study was the deletion of the sequencing pictures as a means of eliciting a written language sample. This was found to be less effective than a given topic in this specific context ('A day I will never forget').

Some secondary modifications were also made to the rest of the test in order to make it more relevant to the present context. These modifications entailed changing names, places, and other Americanisms to more familiar concepts. Care was taken, however, not to make any changes that could alter the purpose of the subtest. 


\section{Analysis of data}

\section{ANALYSIS OF THE ESSAY/STORY}

As different stimulus material was used from that suggested in the TOWL (See Alant 1987, for pilot study results), the TOWL scoring system could not be used. New criteria relevant to the present material had therefore to be developed.

The analytic framework was developed by integrating various procedures used in other tests and assessment techniques eg. Myklebust (1967), Vorster (1983), Hammill and Larsen (1978). The analytic framework used for the description of the data included a global analysis, i.e. an evaluation of the essay as a whole as well as an evaluation of specific language skills used in the essay.

Fifty percent of the original 215 essays were analysed, as this was considered an adequate sample to reflect difficulties in spontaneous writing. The rating was done by two independent raters to ensure objectivity and to include some system of monitoring.

\section{ANALYTIC FRAMEWORK USED}

Framework of the essay: The initial plan or structure around which the essay was constructed.

Is there an introduction i.e. evidence of some preparation of what will follow? - yes/no Are there clearly differentiated paragraphs?

Are there sufficient paragraphs?

Is there a definite ending?

\section{STRUCTURE OF MEANING: GLOBAL EVALUATION}

This criterion refers to the development of meaning within the essay, that is, how language functions as an integrated whole.

What is the general level of abstraction? (Myklebust 1967)

1 Meaningless language/limited language

2 Concrete language/a simple sequence of actions

3 Concrete language, but a more complex description, imaginative eg. some moral to the story, personal reaction, dialogue

4 Abstract-descriptive eg. humour, personal conflict.

\section{Is there any progression of thought in the essay?}

1. None or minimal progression eg. ABGF

2 At times some progression eg. ABC BG: Simple sequence of actions

3 Mostly a clear progression of thought although interrupted at times: definite steps to the end

4 Clear progression of thought/logical.

Is there any connection between sentences?

1 No clear connection/minimal

2 Some connection, mostly not clear

3 Mostly clear connections

4 Well expressed connections.

\section{How explicit is the message?}

1 Not at all easy to understand

2 At times easy to understand

3 Mostly easy to understand

4 Generally well expressed. 
Is there any repetition of thoughts or sentences?

1 Repetition occurs regularly

2 Repetition occurs sometimes

3 Repetition occurs seldom

4 No repetition occurs.

\section{LANGUAGE PROFICIENCY: SPECIFIC SKILLS}

This refers to some specific language skills that can be identified in order to obtain an idea of the student's ability in using language rules within the context of an essay.

Ratings on these scales are based only on the subject's performance in the essay:

1 Generally not appropriate

2 Sometimes appropriate

3 Mostly appropriate

4 Always appropriate.

Language skills were evaluated according to the above scale:

Word order

Word choice

Prepositions

Conjunctions

Tenses

Vocabulary

Punctuation

Spelling

After the scoring, some space was left in order to give the raters the opportunity to write down examples of typical language usage.

\section{SCORING OF THE SUBTESTS}

The three subtests (style, spelling and word usage) were taken from the TOWL test (Hammill and Larsen 1978) and modified in the pilot study in order to increase the relevance of the items for this particular group of students. The scoring of these subtests was conducted according to the outlines provided by the TOWL manual. Only minor changes to the scoring procedures were introduced.

\section{Results}

Firstly, the results of the formal subtests will be presented, followed by the results of the analysis of the stories written by the students.

FORMAL LANGUAGE SUBTESTS: SPELLING, WORD USAGE AND PUNCTUATION

TABLE 2 Means and standard deviations of the students' performance on the subtests (Score out of 25)

\begin{tabular}{lrcrrrr}
\hline Standard & \multicolumn{2}{c}{$\mathbf{6}$} & \multicolumn{2}{c}{$\mathbf{8}$} & \multicolumn{2}{c}{$\mathbf{1 0}$} \\
\hline Subtest: & Mean & SD & Mean & SD & Mean & $S D$ \\
Spelling & 11,49 & 4,14 & 17,05 & 3,77 & 19,43 & 2,56 \\
Word usage & 9,83 & 3,92 & 12,95 & 4,20 & 15,24 & 3,70 \\
Punctuation & 5,94 & 3,07 & 8,67 & 3,72 & 9,22 & 3,19 \\
\hline
\end{tabular}


From table 2 it is clear that there was a systematic improvement of the students' language skills in the higher classes. It is alarming, however, that the average performance of the students was so low, particularly in punctuation and word usage. All three groups of students performed best on the spelling subtest, which could be a reflection of the emphasis placed by teachers on spelling, as it is a structured language skill which can be taught easily by rote.

At the same time, it is interesting that the students obtained low scores on the punctuation test, which could also be regarded as a highly technical and structured skill. However, as punctuation is closely linked with the ways in which meaning is conveyed in writing, the low scores could be a reflection of an insensitivity towards the necessity of punctuation in conveying adequately written messages. This finding could also reflect a vagueness or lack of specificity in the formulation of messages, in that the reader is expected to make his or her own interpretation (Labov 1972).

\section{RESULTS OF THE SUB-TEST STORIES/ESSAYS}

\section{Global evaluations of the essays:}

\begin{tabular}{|c|c|c|}
\hline Framework & Yes & No \\
\hline Introduction & $16 \%$ & $84 \%$ \\
\hline Clear paragraphs & $25 \%$ & $75 \%$ \\
\hline Sufficient paragraphs & $23 \%$ & $77 \%$ \\
\hline Definite ending & $31 \%$ & $69 \%$ \\
\hline
\end{tabular}

From the above table it is clear that few students could structure their essays adequately in terms of an introduction, body and ending or conclusion. Although this could have been a reflection of an inability to finish the essay or story in the given 20 minutes, most of the students did in fact complete their stories, indicating that the time allocated was not too short. The absence of structure in the writing could possibly be related to a difficulty in understanding and, therefore, using the underlying schemes in essays or stories. In this regard, the theoretical and practical applications of the approach of story grammars (Stein and Glenn 1979) could be a useful framework to interpret these difficulties. This approach maintains that unless an individual understands the underlying structure (or map) of written or oral information, he or she will not be able to interpret the material in a satisfactory manner. Interpretations might be made on a superficial level, but understanding will be limited. Consequently, it might be expected that the individual would have difficulty in structuring his or her own spontaneous expressions in terms of a logical scheme.

As indicated overleaf in the formal subtests, the findings in figure 1 also confirm systematic improvement in the language skills of the students over the years of schooling. This figure, however, emphasizes that the general English language performance of this sample of students was poor, as indicated by an average of a score of 2 (which could be equivalent to $50 \%$ ) on all language aspects tested for standard 10 pupils. It is also necessary to take into account that a story (narrative) was used for the evaluation of these skills, as this is generally considered to be the easiest context in which to use language. If, therefore, the language skills of the students were evaluated in a different language context demanding different language functions, their performance could have been even lower.

It is interesting that students generally performed better on the specific language skills as evaluated by the formal subtests as well as the ratings on the essays than on the more global (meaning orientated) evaluations of abstraction, progression of thought, connection between sentences and 
STRUCTURING OF MEANING AND SPECIFIC LINGUISTIC SKILLS

Figure 1 MEAN SCORE OF STD 6,8 AND 10 PUPILS ON ESSAY VARIABLES

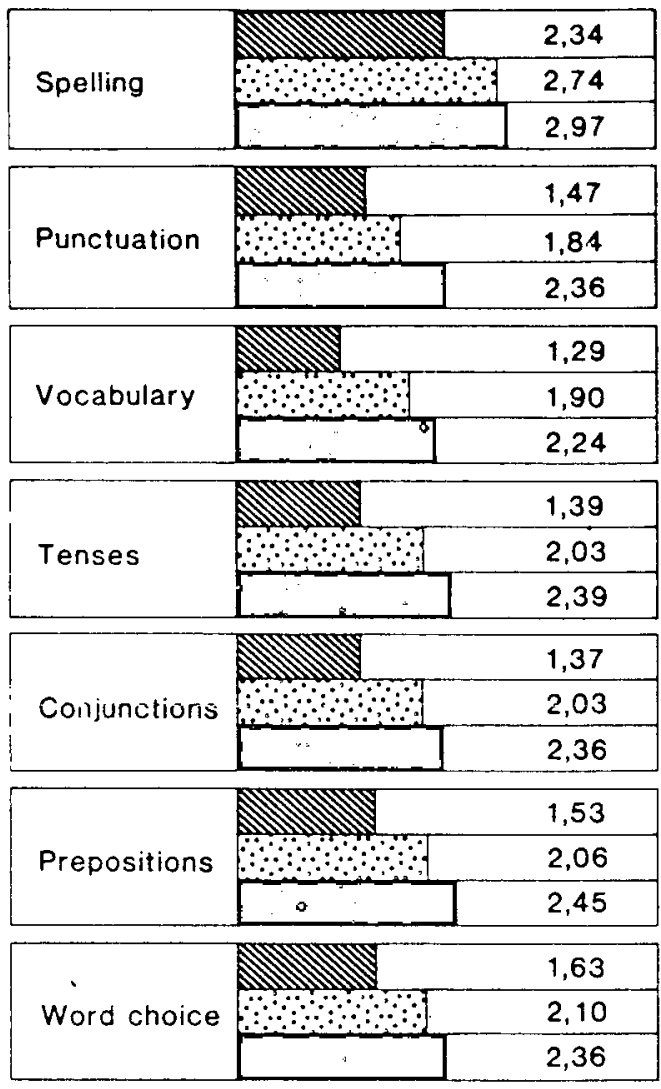
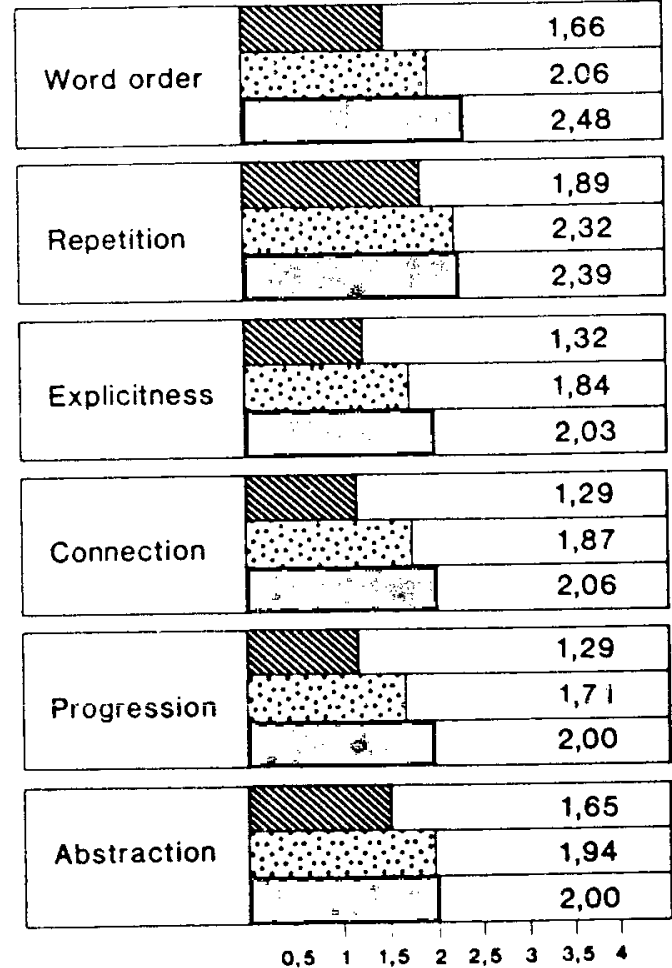

$\begin{array}{lllllllll}0,5 & 1 & 1,5 & 2 & 2,5 & 3 & 3,5 & 4\end{array}$

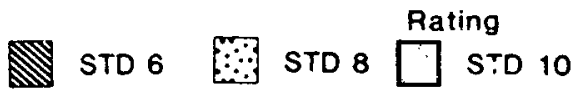

explicitness. This finding indicates that the students experience difficulties in expressing themselves through the written medium, although they do have certain basic language skills. They might know the language rules, but have difficulty in applying them within a specific context, for example an essay (Krashen and Terrell 1983).

One of the most obvious factors contributing to difficulties in applying language within particular contexts is a directive or language teaching approach as opposed to a more naturally oriented language acquisition approach (Krashen and Terrell 1983), where the emphasis would be on functional language rather than on structure. These results could thus be a reflection of the teaching system, as most teachers at the schools reported that attention in the syllabus is almost exclusively focused on the improvement of structured language i.e. the teaching of language rules and spelling. They also confirmed that little attention is paid to spontaneous use or expression of language, as classes are too big, teachers are over-loaded, and little time is therefore available for contextual language use (Odendaal 1985).

A contextual emphasis in language teaching by, for example, essay writing could, however, also be considered as a relatively demanding approach, as integrated language skills are evaluated and developed which require the application of language and communication rules within a specific functional context. Under-qualified or less experienced teachers might, therefore, choose to avoid eliciting and remediating spontaneous language samples because of their own lack of proficiency in English (Mawasha 1986, Odendaal 1986). 
In conclusion, the use of language in a particular context presupposes an understanding of the ways in which language functions within that context. This implies that the user must have some insight into the cultural and thought processes that lead to the ways in which language is expressed and interpreted in order to develop meaning (Schumann 1986). The knowledge of certain language rules, therefore, does not necessarily facilitate integrated language functioning. The effectiveness of any language programme would necessitate the familiarizing of the students with the context or cultural background against which the English language is used. Equally important, however, is the realisation that the experience of the students should be central to language teaching to ensure the relevance and usefulness of what is learned.

It is against this background that second language teaching in schools needs to be examined. Although a single study in a particular area cannot be used as a basis for generalisation, the findings of this study are certainly alarming, particularly since English could be viewed as a major means of access to the education system, the job market and the urban-industrial complex in general.

\section{Implications for the development of an English teaching or intervention programme}

In any approach to second language teaching, the following factors are of primary importance:

(i) Language should be taught in a natural context (Krashen and Terrell 1983). The emphasis should be on second language acquisition (an indirect or global approach) as opposed to second language learning (a direct or specific skills approach, focusing on rules). Teacher training and in-service training programmes to facilitate a more natural approach towards second language teaching are pertinent in order to ensure a meaning-centred approach to language teaching.

(ii) Care should be taken to help the student to develop an understanding of the thought processes behind a particular way of expression. This implies that intervention should focus on an integrated approach.

(iii) "When a student is exposed to a new language, the first internal hurdles are posed by the individual's emotional state and motivations" (Burt, Dulay and Krashen 1982:4). Krashen and Terrell (1983) refer to the "affective filters" of the individual that determine the eventual success with which the student will master the second language. As not much environmental support is given to black students for the learning of English (Malefo 1986, Mawasha 1986), this factor would be of great significance in the formulation and successful application of a programme.

\section{Acknowledgements}

This research has been sponsored by LEARNING TECHNOLOGIES, a Pretoria-based corporation specializing in inter-active video as computer based education.

\section{References}

ALANT, E. 1987. The relevance of the test of written language within a South African context. Paper presented at SAALED conference: University of the Witwatersrand.

BURT, M; H. Dulay \& M. Finocchiaro. 1977. Viewpoints on English as a second language. Regents Publishing Company, New York.

DUlAY, H; M. Burt \& S. Krashen. 1982. Language two. Oxford University Press, New York.

GARDNER, S. 1986. Progress through learning? Africa Insight, 16, 3, 184-189.

HAMMILL, D.D. \& S.C. Larsen. 1978. Test of written language. Pro-ed Publishers, Austin.

KRASHEN, S.D. \& T.D. TERRELL. 1983. The natural approach: language acquisition in the classroom. Pergamon, Oxford. 
LABOV, W. 1972. The logic of nonstandard English. In Giglioli, P. (ed). Language and social context. Penguin, New York.

MALEFO, B.M. 1986. The environment outside the school. In HSRC-Report, The role of language in black education. HSRC, Pretoria.

MAWASHA, A.L. 1986. Medium of instruction in black education in Southern Africa. In HSRCReport, The role of language in black education. HSRC, Pretoria.

MYKLEBUST, H.R. 1967. Development and disorders of written language. Grune and Stratton, New York.

ODENDAAL, M.S. 1985. Needs analysis of higher primary teachers in KwaZulu. Per Linguam, Special issue 1 .

ODENDAAL, M.S. 1986. Die milieu binne die skool. In HSRC-Report, The role of language in black education. HSRC, Pretoria.

OVANDO, C.J. 1985. Bilingual and ESL classrooms. McGraw-Hill, New York.

RAMIREZ, A.G. 1985. Bilingualism through schooling. State University of New York Press, Albany.

SCHUMANN, J.H. 1986. Research on the acculturation model for second language acquisition. Multilingual and multicultural development. 7, 5, 379-391.

STEIN, N. \& GLENN, C. 1979. An analysis of story comprehension in elementary school children. In Freedle, R. (ed). New directions in discourse processing. New York, Ablex.

VORSTER, J. 1983. Test of Language Proficiency (TOLP). HSRC, Pretoria. 